\title{
Manufacturer Recall
}

National Cancer Institute

\section{Source}

National Cancer Institute. Manufacturer Recall. NCI Thesaurus. Code C100045.

An imperative issued by the manufacturer of a device that the device needs to be returned to a designated source for repair or replacement. (ACC) 